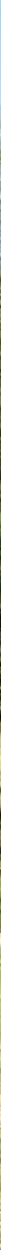

\title{
Löbau - Die Stadt im Grünen
}

\section{Karin Schönlebe}

Noch ist der grüne Ring um die Altstadt von Löbau intakt. Alte Kopflinden säumen die Promenaden und laden zum Verweilen ein. Wenn auch der Zeit angepasst nicht mehr so viele Beete $\mathrm{zu}$ sehen sind, so wurden diese doch durch Schalen und Kübel bis in das Zentrum der Stadt zu einem Blütenmeer ersetzt.

Es werden der Saison entsprechende Bepflanzungen durchgeführt, vor denen so manch ein Liebhaber nicht die Hände lassen kann.

Wenige Städte haben das Glück, direkt in der Stadt ein riesiges Areal einer ehemaligen Landesgartenschau zur Erholung zu behalten. Der gleichnamige Fluss, das Löbauer Wasser, durchzieht die Stadt mit seinen Windungen und Kurven. In den letzten Jahren hat er wieder den Stand eines Salmoniden-Gewässers erreicht, in dem also auch Lachse oder Forellen leben könnten. Gleich danach erhebt sich einladend der Hausberg von Löbau, der Löbauer Berg, welcher seit 1938 auch den Status eines Landschaftsschutzgebietes besitzt. Der aus einem erloschenen Vulkan entstandene Sattelberg ist dicht bewachsen mit einem Bergmisch- wald aus Eichen, Hainbuchen und WinterLinden. Dem Besucher eröffnet sich immer wieder der Blick in das Land. Viele Bänke und Aussichtsplattformen laden zum Verweilen ein. Verschiedene Gastwirtschaften laben den Wanderer. Ein Höhepunkt für den Wanderer ist die Besteigung des Gusseisernen Turmes. Die Inschrift von Ludwig von Klitzing ist hier großartig zu erfahren: „Je weiter der Blick, desto freier das Herz".

Aber nicht nur die schönen Aussichten locken jährlich viel Besucher auf den Berg. Eingeweihte geben gerne ihr Wissen preis, und so kann

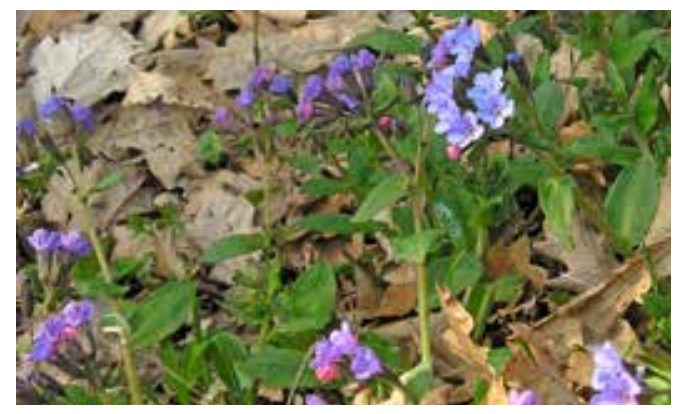

Bau einer Weidenkirche auf dem Gelände der Landesgartenschau
Lungenkraut (Pulmonaria officinalis) 


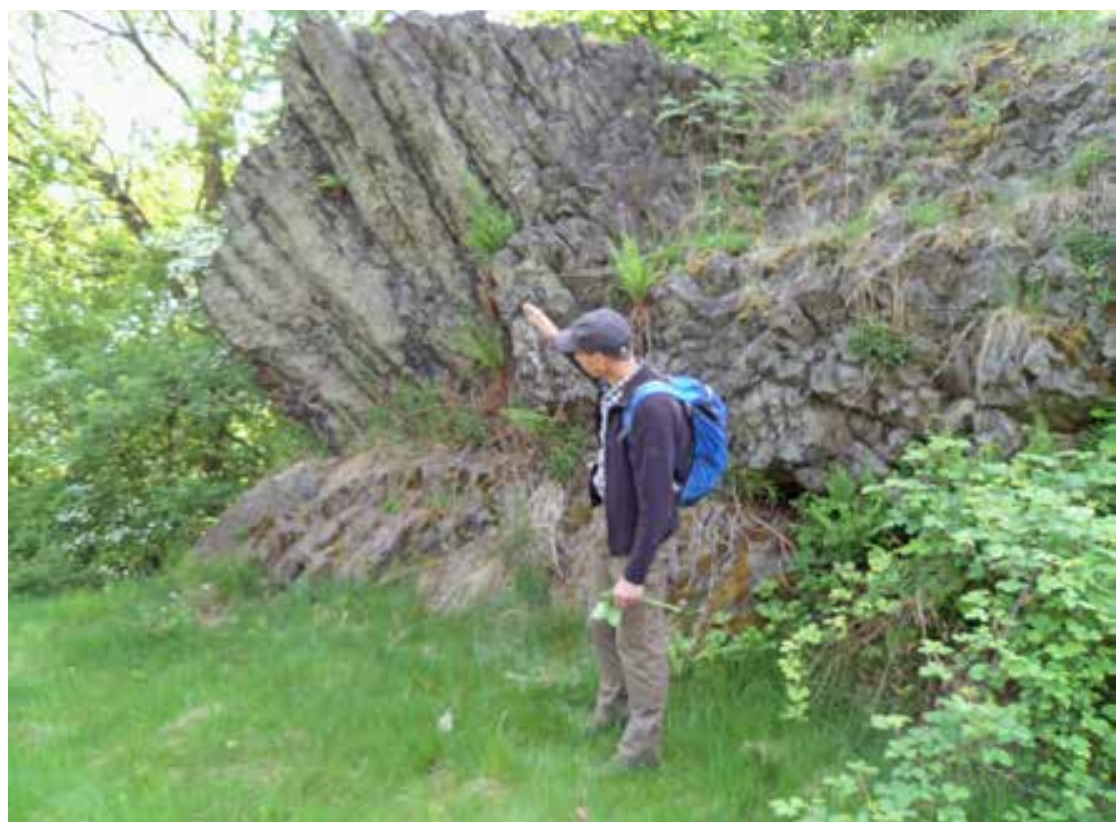

Basaltformation am Löwenköpfchen

Auf dem Naturlehrpfad

Autorin

Karin Schönlebe Stadtverwaltung Löbau Bauamt

Umweltschutz

Altmarkt 1

02708 Löbau man die Orchideenwiese, welche versteckt zwischen den Fichten liegt, bewundern oder aber auch auf die Suche nach einem verlorengegangenen Botanischen Garten gehen. Dieser befindet sich am „Alten Steinbruch“ und wurde vom Humboldtverein 1914 als Pflanzenschutzgarten für Gebirgsflora angelegt. Die Vegetation ist sehr artenreich, ca. 21 Prozent aller Pflanzenarten der gesamtdeutschen Flora sind auf dem Löbauer Berg vertreten. An der Oskar-Rolle-Bank findet der interessierte Besucher das kleine Waldvögelein und in den Nischen der Basalthalde die natürliche Eibe. Die verschiedenen Charakterbilder spiegeln sich wieder. Trockenflora auf den Basaltblöcken oder Schatten liebende Pflanzen auf den Schattenhängen.

Der Berg ist ebenfalls mit vielen gutmarkierten Wanderwegen überzogen. So befindet sich ein Stück des Fernwanderweges von Görlitz nach Greis auf dem Berg oder ein Stück des heimatkundlichen Naturlehrpfades und weitere Ge-

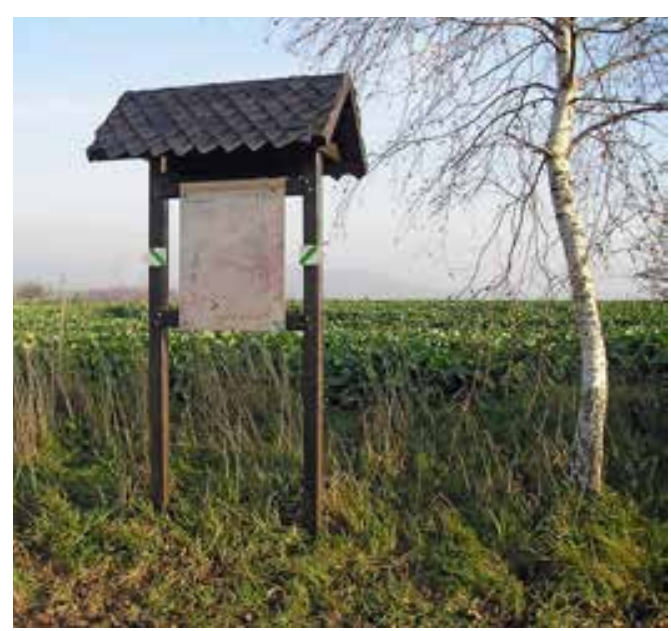

bietswanderwege. Seit 1974 ist er stolzes Landesnaturschutzgebiet. In Sichtweite ist ein weiteres natürliches Kleinod der Oberlausitz, der Rotstein. Er ist bekannt für seine ausgeprägte Flora und Fauna.

Die Leberblümchen, welche ganz üppig im Frühling blühen, werden von den Schlüsselblumen abgelöst. Ferner findet man den Seidelbast oder auch die wilde Gladiole. Kenner der Region finden auch die Türkenbund-Lilie. Großangelegt wurde die „Haselmausjagd“ auf dem Rotstein. Keine Angst, hier wurden die Tiere nicht erschossen - nein, ihnen wurde der Lebensraum besonders zuträglich eingerichtet. Mit solchen Aktionen wurden Haselnusssträucher und andere natürlichen Gehölze für sie angepflanzt.

Nach der anderen Seite der Stadt befindet sich der Bubenik. Auch er besteht aus einem Doppelgipfel. Auf einer befindet sich eine Basaltsäulenformation, die wegen ihrer Form auch „Löwenköpfchen“ genannt wird.

Der nördliche Gipfel wird wegen seiner Ähnlichkeit zur Görlitzer Landeskrone auch „Kleine Landeskrone“ genannt. Wieder finden wir hier botanische Raritäten. Die Orchideenart VogelNestwurz oder auch der Doldenblütler Sanikel ist hier zu finden. Der Naturlehrpfad, welchen wir schon auf dem Löbauer Berg begegnet sind, erschließt auch hier das Gebiet. Immerhin ist er ca. 40 Kilometer lang und umrundet die Stadt Löbau.

Nicht auf Berge, sondern in das Tal der Löbau bewegen wir uns, wenn wir die Georgewitzer Skala betreten. Das ist ein ca. 1,3 km langes Felsental, welches von der Löbau geschaffen wurde. Die Laubwaldgesellschaft und das Aufkommen der geschützten großen Vogelmiere, des hohlen Lerchensporns, des dunklen Lungenkrautes oder wie das Maiglöckchen brachte ihr 1961 den Status des Landschaftsschutzgebietes ein. Hier kann man wunderbar am Wasser oder auf dem Naturlehrpfad entlangwandern und dem Eisvogel oder auch der Gebirgsstelze zusehen. Alles strahlt eine enorme Ruhe und Besinnlichkeit aus.

Und auch wenn der Höllengrund in Großschweidnitz kein Landesnaturschutzgebiet ist, so ist diese 900 Meter lange Schlucht zwischen steilen und unausgeglichenen Hängen eine Besonderheit in seiner Waldform. Entlang des Großschweidnitzer Wassers, welches den linken Quellbach des Löbauer Wassers darstellt, befinden sich Berg-Ahorn, Eschen und Eichen. In Richtung Norden übernehmen aber eher die Fichten das Zepter und auf den Südhängen erkennen wir vorwiegend Kiefern und Lärchen. Wer hat schon so einen Kompass dabei? 